\title{
Reform of Database Course in Police Colleges Based on "Working Process"
}

\author{
Gao Jian \\ Information technology and network security College, People's Public Security University of China, BeiJing,China \\ Email: gaojianbeijing2006@163.com
}

\begin{abstract}
According to the actual research results, combined with the teaching experience, this paper puts forward the reform method of the database course in police colleges. Based on the actual sector capacity requirement analysis, design of the five learning steps and four teaching scene, the task driven, project oriented, make students doing, learning by doing, students are required in the network security supervision work in the operation skill and ability.
\end{abstract}

Index Terms-Database; Working Process; Process Assessment

\section{INTRODUCTION}

At present, some developed countries in the international education system, education course structure more perfect, after many years of practice is relatively mature, the typical education curriculum model mainly includes: MES CBE curriculum model, curriculum model, the "dual system" mode.

\section{A. MES curriculum model}

MES curriculum model is the of Employable Skill Modules (employment skills module) curriculum model for short, is the international labor organization after 14 years of research and development of the curriculum system[1]. MES curriculum model is based on work analysis and focus on practical skills needed in the production activities, the work system of five level decomposition, finally obtain the basic modules, and each module covers the six basic knowledge needed to complete the task, teaching skills and knowledge required for unit unity that broke the knowledge boundary, realize the integrated curriculum. Strict and accurate characteristics of MES curriculum model, organization in the process of curriculum development are very strict, each step is closely related to cohesion is very clear, to ensure the scientific results. And the course content requires the operator to carry on the fine technical operation, has the standard skilled operation skill[2]. But it is easy to pay too much attention to the details of the action and ignored the overall requirements.

\section{B. CBE curriculum model}

CBE course is Education Competence-based (competence based education). Ability based curriculum model originated in the United States, Canada, in the end of 1960s to form a DACUM as the core of the curriculum development technology[3]. It is by the enterprise experts committee in the form of occupation ability analysis, determine the occupation ability standard for a job complete, obtains the knowledge, attitudes and skills required for a task, and then to the student's personal learning guide the related knowledge and learning skills, in order to meet the standard requirements of the curriculum model. It is the way to take individualized learning to help students to establish confidence and develop independent habits[4].

\section{Germany's dual system}

The implementation of the dual system of German occupation education mode, began at the end of the 1960s, "dual" is to participate in the occupation education students and students with a business apprentice of double identity, schools and enterprises jointly run the occupation education, combined with practical skills and theoretical knowledge[5]. The dual system of curriculum model from the analysis of the actual occupation of the scientific analysis of the typical projects included in the social work occupation and practical application, through summary form typical occupation groups, each group corresponds to the typical occupation of a professional, will constitute the "occupation training"[6]. The German "dual system" curriculum mode to cultivate students' ability in the future employment competitive ability, adaptation and development, found that the comprehensive occupation ability problem, analyze and solve problems in actual work. Therefore, the German "dual system" is regarded as the German economy after World War II, the rise of the miracle of the secret weapon, is the core of German vocational education, has become a successful example of the world's Vocational education[7].

With the development of social economy and reform, the "dual system" vocational education model has exposed some shortcomings, and has encountered severe challenges[8]. After 1990s, the German based on traditional "dual system" curriculum, a new round of change and reform, put forward the model of "learning field" program, which aims to make the teaching of occupation training occupation education in school and enterprise can more effective coordination and cooperation. The occupation technology education in Germany once again to promote the development of the German economy, to achieve economic take-off. In order 
to cultivate students' professional ability, the course design based on the work process is based on the work process, and the teaching action is the guide. "Learning field" occupation education curriculum scheme was put forward, it attracted the attention of scholars and occupation education, government and research institutions put forward in the part of the occupation training "to" learning field curriculum program, which greatly promoted the development of the course of the 2003, the program began in Germany widely and become a new paradigm for occupation education curriculum reform in Germany[9][10].

"The principle and technology of" database courses in public security colleges is network security and law enforcement professional core courses, mainly in order to cultivate students' information processing and retrieval capabilities in the face of massive data, to enable the students to grasp the common database establishment and maintenance, management and application, development and design, backup and restore capabilities.

Learning field curriculum development is based on the work process as shown in Fig1. The basic idea is to derive the relevant "learning field" in all vocational "action areas" closely related to the vocational activity system, and then through the "learning situation" suitable for teaching.

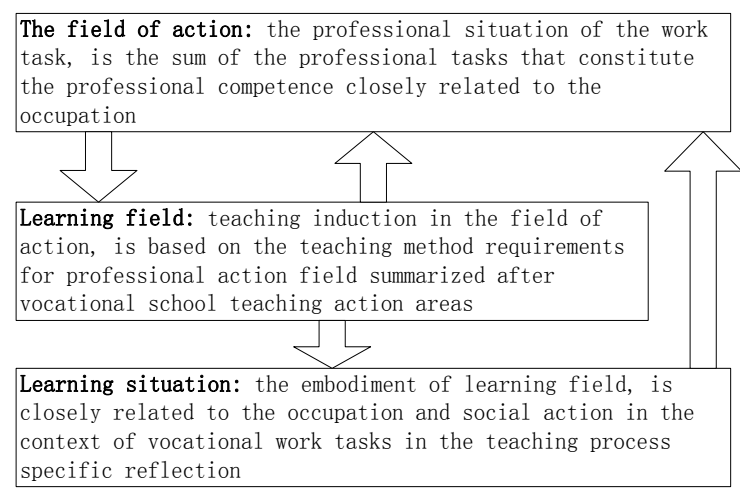

Fig.1. Action field,learning field,learning situation relation

\section{CURriculum ORIENTATION AND JOB SKILLS REQUIREMENTS}

According to the content of the course database, network security supervision department of Dalian, Beijing, Kunming city to carry out a full investigation, combined with the feedback of previous graduates, according to the database management, network monitoring work needed for students engaged in maintenance, operation of the specific content of the work, the training target of database course in the skills of practical talents. Network security and law enforcement professionals in public security college students after graduation employment is the main direction of the county and cities network safety supervision departments, and the network supervision work, often face a large amount of data is suspect, so students need to be familiar with the database configuration, database design, proficient in database retrieval. While in the traditional database teaching, students' understanding of the database is limited to theory, even for some of the commonly used database are not hands-on installation, operation, for database retrieval, backup, optimization question, so it can not meet the network supervision department daily work demand. Therefore, the goal of this paper is the database of curriculum reform is to enable students to correct the installation and configuration of the commonly used types of database at the end of the course and have the ability of database maintenance, database backup and restore capabilities, but also focus on training students to optimize design, database and other skills.

\section{DeVelopment Process BASED ON THE Working PROCESS OF CURRICULUM}

The development of work process oriented curriculum system is starting from the actual work, the typical tasks as the starting point, analysis of the required skills, will be transformed into the process of learning tasks, to help students gain the ability to engage in the future network security of a job security department required, ensure a student graduates will be able to get started [11]. In this way, the course of the school will break the traditional discipline system under the general, abstract, theoretical limitations, to establish a work around the need for a technical ability and set the course[12]. That is to say the original course design thought and the course system of the subject system that we are familiar with will want to be completely broken. Based on the work process oriented curriculum system development process as shown in Fig 2

$\begin{gathered}\text { Counterpart } \\ \text { unit Research }\end{gathered}$
$\begin{aligned} & \text { Task Analysis: } \\ & \text { Analysis of typical work tasks } \\ & \text { according to the corresponding job } \\ & \text { position and position group }\end{aligned}$
$\begin{aligned} & \text { Summary of Action: } \\ & \text { According to the complexity of the } \\ & \text { ability to integrate a typical task, the } \\ & \text { formation of the field of comprehensive } \\ & \text { ability }\end{aligned}$
$\begin{aligned} & \text { Learning area Conversion: } \\ & \text { According to the development of } \\ & \text { professional ability, the course of } \\ & \text { action field is transformed into the } \\ & \text { curriculum. }\end{aligned}$

Fig.2. Based on the working process curriculum system development process 


\section{DATABASE CURRICUlum REFORM BASED ON WORKING PROCESS}

Work process is an individual "to complete a task and get the results of the work carried out a complete working process", is from the field of professional action in the process of work[13][14] Curriculum design based on the work process can stimulate students' interest in learning, so that students learn skills in the task, and the work process of public security work is very fit.

The traditional curriculum curriculum syllabus database mainly includes: Database Principle overview, data model, ER model, analysis paradigm SQL statement and the data object use, database storage principle, index and query, data warehouse and data mining[15]. Based on the database of curriculum design process, according to the network safety supervision departments usually work for the common operation of the database, the database operation steps are divided into: database installation and configuration, database management, and the use and development of database design, database backup and restore, database optimization. As shown in Fig 3:

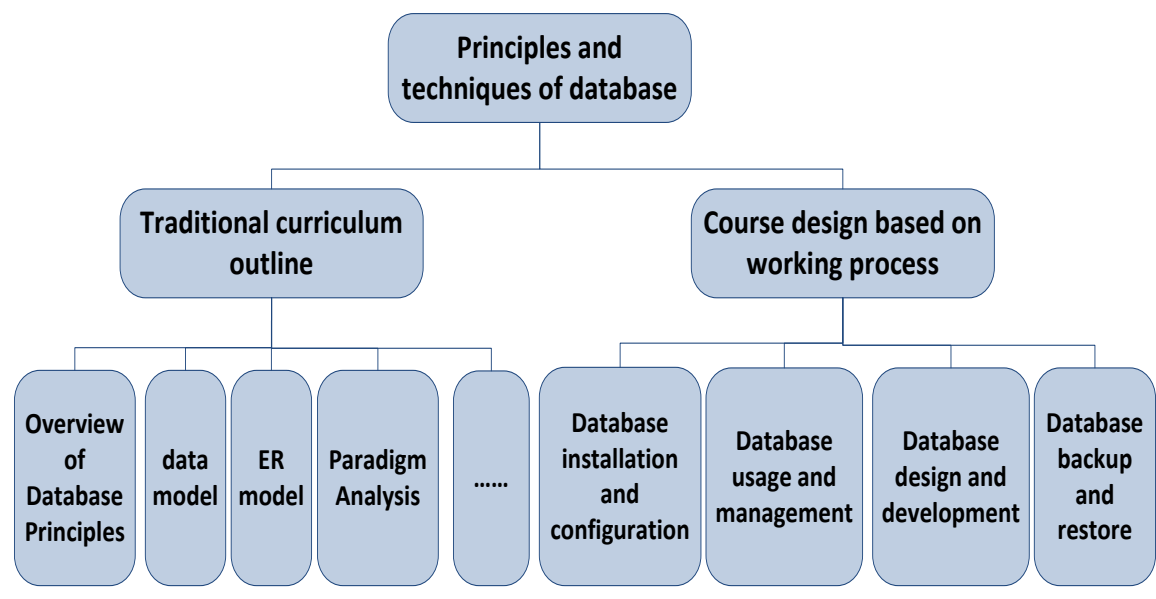

Fig.3. Comparison of traditional database outline and curriculum design based on working process

According to the operation steps of the database, set up different working scenarios, and then reconstruct the corresponding database knowledge. In the whole process of teaching, different scenes repeat steps, not teaching content[16][17]. For each database to install configuration, use and management, development and design, backup and restore and optimization steps, but different database of these steps is different, different operating system platforms of these operations are also different. So in this paper, we set up four teaching scenarios, as shown in Fig 4. The difficulty level of each scene is from low to high, and the database and operating system platforms used in each scene are also different. This not only covers a variety of commonly used database, but also related to different operating system platform.

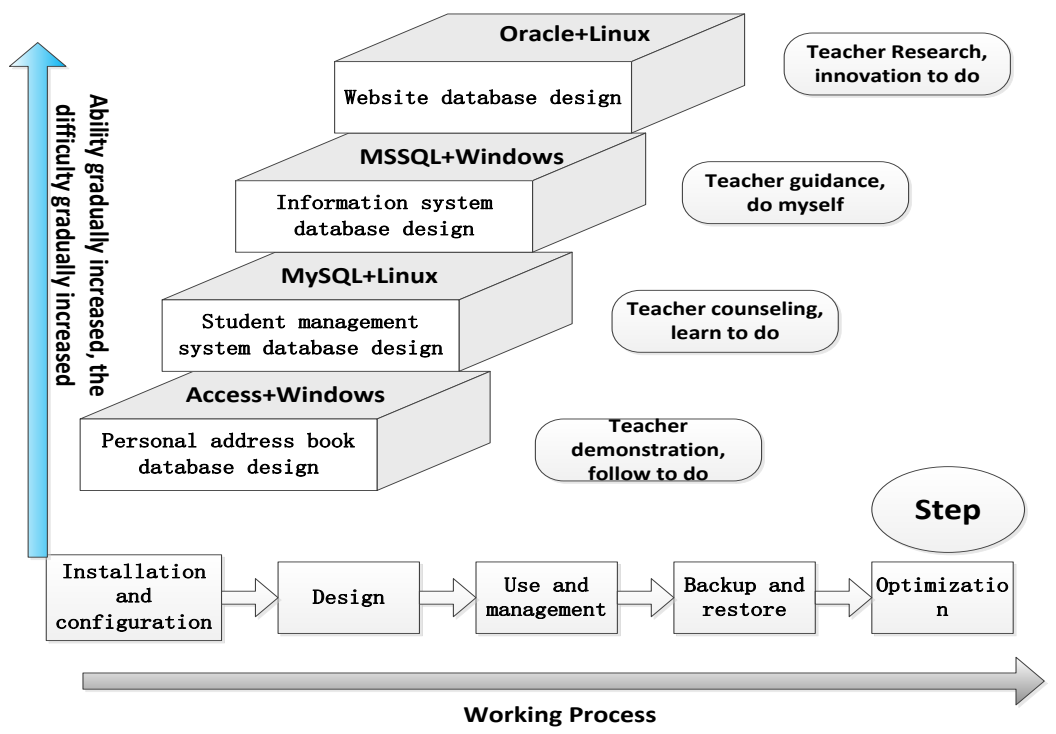

Fig.4. Database curriculum design based on working process 
For each scene involves the knowledge point and the focus is different, the scene a "personal mail list database", mainly in order to let the students start from a simple database platform of windows Access, have an overall understanding of the knowledge database, which includes: the composition of the database of the basic concepts and terminology the development of database, data, and relational model data structure. In this process is the main explanation and demonstration of teacher, students to follow.

In the design of a complete scene after the students have a general understanding of the database, enter the scene two "learning student database management system, Linux platform based on the MySQL database selection in this scene, students can experience a different installation method of the data platform and operation method, the knowledge points in the scene second, the design method of relational database design and use E-R diagram, design the student database, create a database table and the method of data input, update, delete, query and other operations, in this process, students can according to the teacher's explanation and an example, learn to build database.

Third, select a common public security information system as the object of operation, and select the commonly used enterprise class database MSSQL as an experimental tool. In this process can make students more in-depth understanding of the design of database information system in public security work, related to the knowledge points include: the use of SQL language, SQL to create database and data table, the SQL statement to insert, delete, modify, query, security mechanism of SQL Server, the management of database users and roles, database backup and recovery. In this process, students can according to the teacher's explanation and guidance, to build their own database and complete the task.

Scene four, using the Linux platform based on the Oracle database and select the Internet business website as the research object. Through the scene four of the training, students can be familiar with the web site of the database is how to design. Mainly related to the knowledge points are: the preparation of the stored procedure, the establishment of index, the trigger, and the realization of data integrity.

\section{TEACHING METHOD}

From a macro point of view, based on the working process of the implementation of "Database Principle" integration of teaching courses, the author mainly adopts the action oriented teaching method, student centered, teacher guide. Let the students learning and skills training in the occupation training room with real situation, in the implementation process of project tasks, students master the professional knowledge and skills, social ability, ability has also been training, set up their own work experience and ability system. That is driven by a mission to allow students to active learning, teachers play a major organizer in the teaching process, the main work is assigned learning tasks, requirements and objectives and to enable students to understand the learning tasks; second is the working process to guide students to complete the task of learning, to help students control their working process, to give students more independent learning space.

On the micro level, the author uses the teaching method of project teaching method, guiding grammar and role playing method. Project teaching is student-centered, student organizations, according to a team to solve problems or difficulties to complete the project tasks, teachers play a guiding role in the whole process and the organizers of the completion of the project, also the teachers guide students to complete the whole process of the project, to grasp the teaching content of this teaching method the process of middle school students. In under the guidance of the author, a relatively independent "home wireless network security protection project to give students completed their own collection of information, design and implementation of the project decision task, finally by the students responsible for their own mutual evaluation, the students through the implementation of the project, can grasp the basic requirements of the project work flow and the link the. So that students have a strong interest in computer network security courses, in the project teaching students professional knowledge has been comprehensive application, analysis of problems and problem-solving ability has been improved. Guiding text teaching method is a very important teaching method in vocational training. It requires learning less with the guidance of the text to complete the task independently. Guide paper is written by the teachers to develop tasks, it includes the task of introduction, guidance, work plans and assessment of the table, etc.. By guiding the students to complete the task of action oriented learning independently. Role play teaching method is to design a mentor task in the classroom, and guide students to participate in teaching activities, let students play a variety of roles, role into the scene, to deal with various problems and contradictions, to deepen the understanding of professional knowledge and flexible use of purpose.

\section{EXAMINATION MODE REFORM}

At present, the public security colleges and universities on the database related to the traditional mode of assessment is basically a closed book written in a closed manner, the general teaching week for eighteen weeks, 34 hours per week, Twentieth weeks for the final examination. The problems existing in the traditional assessment methods are:

First, students attach great importance to the final results, rather than the practical ability, easy for students to learn the mistake, even some students think the operation courses can also by rote.

Second, for the traditional assessment methods, students despise the usual study, pay attention to the end of the assault review, there are a lot of plagiarism in the examination process. 
This paper puts forward a method of process assessment for the course of database principle and technology. That emphasis on the study of the process of assessment, usually accounted for seventy percent of the results, the final grade accounted for thirty percent. The scores of the scores of the ordinary times come from the realization and comprehension of the four scenes, and put some concepts and properties into the final examination. So that students pay attention to the normal learning, each scene of the training is done, the completion of a database from the installation to the optimization of the steps to achieve their own works. At the same time because of the assessment results of the seventy percent in the usual assessment has been identified, but also to avoid the end of the period to conduct a review of the phenomenon of the phenomenon.

\section{CONCLUSION}

Based on the working process of the "database principle and technology" curriculum reform, designed for the public security colleges and universities network security and law enforcement professional students to provide application oriented teaching model[18][19]. In the teaching process, teachers set up different teaching scene, knowledge reconstruction in the textbooks, and cleverly inserted into specific scene task, let the students finish the tasks in a particular scene at the same time, to acquire knowledge, improve skills. This kind of teaching method, which is based on the work process and takes the scene task as the driving method, can help students to cultivate innovative thinking and improve the ability to solve problems in practical application[20][21].

The following suggestions are given to the students in public security colleges:

\section{A. Excellent political, fine style, the ability of the team building}

Excellent political, fine style is the basic quality of the police force, in the network security personnel training is beyond doubt. For the ability to integrate a variety of capabilities, familiar with the law, according to the law, to a good public security business capacity and technical capacity to respond to the number of law enforcement officers a serious shortage of network security. At the same time we must have the ability to innovate, and constantly on the new issues of public relations, in order to adapt to and respond to the changing times of the internet.

B. School cooperation, school enterprise cooperation, the idea of the school board to strengthen cooperation

Training network security personnel need to strengthen cooperation school cooperation, school enterprise cooperation, school administration, indulge in selfadmiration harmful, only to go out, and other schools, and strengthen the enterprise network security combat unit of exchange, see their advantages, improve their own shortcomings, to better improve the personnel training mechanism.
Construction of cooperative school cooperation, school enterprise cooperation, bureau, strengthen collaborative innovation construction, strengthen communication with other public institutions, exchange of educational ideas; in-depth mainstream network security companies to learn new technologies and new methods to understand the new developments; in-depth grass-roots public security requirements, the public security, to seek their own development, and realize the line needs standards, vigorously improve the quality of education and to cultivate practical talents for the police, through the core technology to enhance combat network security personnel of the public relations ability, this exercise in education on the basis of network security, combat personnel training and the introduction of the network security department will give fresh blood, so that the network security department the new vitality[22].

At the same time, school cooperation, school enterprise cooperation, school cooperation, but also to promote curriculum reform, teaching materials, change the current teaching methods and assessment methods, highlighting the actual combat ability of students. School enterprise and three party Bureau of mutual support, mutual penetration, three to intervene, complementary advantages, resource sharing, benefit sharing, is to realize the modernization of education, promote the development of productive forces, an important way to the education and the sustainable development of production. The combination of production, learning and research is an effective way to promote the development of science and technology, economy and enterprise. The cooperation of schools, enterprises and bureaus is an important way to improve public security education and train talents[23].

\section{Build a strong "double qualification" teachers team.}

In the course of implementing the integrated teaching, the work place, the training room and the classroom are integrated into a whole, the teacher not only teaches the theory, but also guides the practice. So teachers need to have a solid professional theoretical knowledge, but also has a good operating skills and rich practical experience, and master the network security management and maintenance of the work of the dynamic. To solve this problem, it attaches great importance to the construction of secondary vocational school teachers, teachers should regularly send business practice, encourage teachers to participate in technical research enterprises, teachers regularly participate in professional and technical training to the enterprise or enterprises to invite experts to the school teachers in the training of teachers, the professional teachers to understand the new trends of network technology. Update the knowledge structure of professional teachers, in order to strengthen the construction of the integration of teachers, to ensure the smooth implementation of the integrated teaching based on working process.

\section{REFERENCES}

[1] Sun F. The Software Technology Curriculum System Construction in Higher Vocational Education Based on 
Working Process[J]. Journal of Tianjin Vocational Institutes, 2008, 49(9):1537-45.

[2] Liu Z. The Curriculum Development Method Based on Working Process[J]. Journal of Qingdao Technical College, 2008.

[3] Liu D. Reform and Practice of the Course of "Oil Analysis Technology" Based on Working Process[J]. Journal of Hubei Correspondence University, 2016.

[4] Wen G D. Technolegy of electic-measure course based on working process in high technique school[J]. Journal of Chongqing University of Posts \& Telecommunications, 2008.

[5] Ying M A, An-Ying Y E, Xuan M A, et al. Teaching Research on Mechanical Drawing of Vocational Education Based on Working Process[J]. Journal of Engineering Graphics, 2008.

[6] Li Y. Designing Syllabuses and Execution based on Working Process:a Case Study of the Course,Business Etiquette[J]. Journal of Tianjin Institute of Financial \& Commercial Management, 2009.

[7] Tong M, Shu J, Chen D. Study on Course Development of Production Technology of Organic Chemical Industry Based on Working Process in Higher Vocational Education[J]. Guangdong Chemical Industry, 2010.

[8] Wang Y, Ma C. Practical Research on Curriculum System Constuction of Chemical Engineering Specialty Based on Working Process in Higher Vocational College[J]. Guangdong Chemical Industry, 2011.

[9] Shao G L. Analysis on Subject Librarian's Performance Assessment System Based on Working Process[J]. SciTech Information Development \& Economy, 2013, 45(9):2017 - 2020.

[10] Guo Z. Discussion about Teaching Reform in Basis of Mechanical Designing Based on Working Process[J]. China Educational Technology \& Equipment, 2015.

[11] Chen H, Huang H, Wang L, et al. Research and Application of Blended Learning in Distance Education and Teaching Reform[J]. International Journal of Education \& Management Engineering, 2011, 1(3):334337.

[12] Li D, Liu C, Liu B. H-RBAC: A Hierarchical Access Control Model for SaaS Systems[J]. International Journal of Modern Education \& Computer Science, 2011, 3(5).

[13] Iraji M S, Aboutalebi M, Seyedaghaee N R, et al. Students Classification With Adaptive Neuro Fuzzy[J]. International Journal of Modern Education \& Computer Science, 2012, 4(7).

[14] Khan M N A, Khalid M, Haq S U. Review of Requirements Management Issues in Software Development[J]. International Journal of Modern Education \& Computer Science, 2013, 5(1).
[15] Zhao J J, Xiang X Y, Zhi-Yong H U, et al. On ProjectOriented English Teaching Mode of Higher Vocational Colleges Based on Working Process[J]. Journal of Chengde Petroleum College, 2016.

[16] Huang L D, Zhou X R, Polytechnic E. Construction and Implementation of Mould Major Curriculum System based on Working Process Direction[J]. Times Agricultural Machinery, 2016.

[17] Zou X Z. Thinking of Teaching Optimization of Mechanical Practical Course in Higher Vocational Colleges Based on the Working Process[J]. Times Agricultural Machinery, 2016.

[18] Fernandes B K C, Guedes M V C, Silva L D F D, et al. NURSING PROCESS BASED ON VIRGINIA HENDERSON APPLIED FOR A WORKING ELDERLY[J]. Journal of Nursing Ufpe, 2016.

[19] Guo Z. Discussion about Teaching Reform in Basis of Mechanical Designing Based on Working Process[J]. China Educational Technology \& Equipment, 2015.

[20] Ming-Yue P, Teng H H, Shi S Y. Discussion on the Reform of Curriculum System of Environmental Impact Assessment Based on Working Process[J]. Journal of Anhui Agricultural Sciences, 2015.

[21] Ya-Qin D U, Peng D, Yang X K. A Study on the Curriculum Construction of the Course of Engineering Thermodynamics Based on Working Process[J]. Journal of Chongqing Electric Power College, 2015.

[22] Liu J. Skill Teaching Design Based on Working Process:Taking"Transport Operation Training"as an Example[J]. Jiangsu Science \& Technology Information, 2015.

[23] Du Y, Sun N. The application of Quadrifid Graphs Model in content system optimization of the vocational course based on working process 'taking the course of Techniques of Car Sales for example[C]// International Conference on Economy, Management and Education Technology. 2015.

\section{Authors' Profiles}

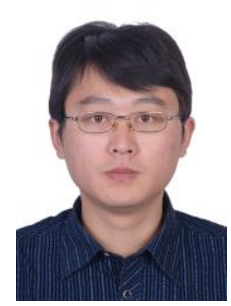

Dr. Gao Jian is a lecturer in information technology and network security college, People's public security University of China . In teaching, he has been focusing on Work Process concepts and Problem Based Learning approaches in Cyber Security Education. In research, his current interests include Botnet, Malware, DDoS.

How to cite this paper: Gao Jian,"Reform of Database Course in Police Colleges Based on "Working Process"', International Journal of Modern Education and Computer Science(IJMECS), Vol.9, No.2, pp.41-46, 2017.DOI: 10.5815/ijmecs.2017.02.05 